\title{
Editorial
}

\section{Introducing Journal of Clinical Research and Applied Medicine}

\section{Pankaj Chaudhary}

Editor-in-Chief

Dear authors and readers,

I am happy to launch a new journal entitled Journal of Clinical Research and Applied Medicine (www. jcramonline.com) dedicating towards the medical and clinical research field. In this journal, we provide a new research report analysing the aspects of basic research/ clinical studies related to the field of medical sciences.

Clinical research is rising due to the advent of new technology and the growing expectation and demand from researchers. The journal aims to promote medical science research, sharing of scientific information, and discussion of regulatory systems that encourage innovative research. JCRAM provides a platform for the most precise and rapid sharing of fresh scientific information to promote timely dissemination of knowledge and idea cross-fertilization.

Journal of Clinical Research and Applied Medicine (JCRAM) strives to provide high-quality peer-reviewed papers and high-performing works in the field of medical sciences to students, researchers, and scientists all over the world. With your kind cooperation and assistance, JCRAM will take great care in getting your article published as soon as possible.

To be featured in future sections of our Journal, I invite any researchers who wish to publish their works in our Journal. I'm looking forward to delivering you the next edition of Journal of Clinical Research and Applied Medicine in three months. We will continue to contribute high-quality research articles and reviews and consider contributing to other sections of the journal.

\section{Scope of the journal}

Journal of Clinical Research and Applied Medicine (JCRAM) aims to help students, researchers, and scientists, worldwide to benefit from high-quality peerreviewed articles and to their high performing works in the entire arena of medical sciences. JCRAM take much care in making your article published without much delay with your kind cooperation and support.

Original research papers, review articles, short communications, case studies, case series are welcomed provided they demonstrate new findings of relevance to the field. All articles will be peer- Researchers, Research reviewed and will find a place in the Journal of Clinical Research and Applied Medicine (JCRAM) based on the merit and innovativeness of the research work. JCRAM hopes that scholars, Academician, Industrialists, etc. would make use of this journal for the development of medical science.

\section{Subjects Include}

Anatomy, Physiology, Biochemistry, Pharmacology, Pathology, Forensic Medicine, Microbiology, ENT, Ophthalmology, Preventive and Social Medicine, Internal Medicine, Surgery, Obstetrics and Gynecology, Pediatrics, Anesthesiology, Radiology, Skin and VD, TB and Chest, Psychiatry, Dentistry, Clinical Epidemiology, Biomedical Engineering, Pharmacy, Nursing/Paramedical, Digital Health.
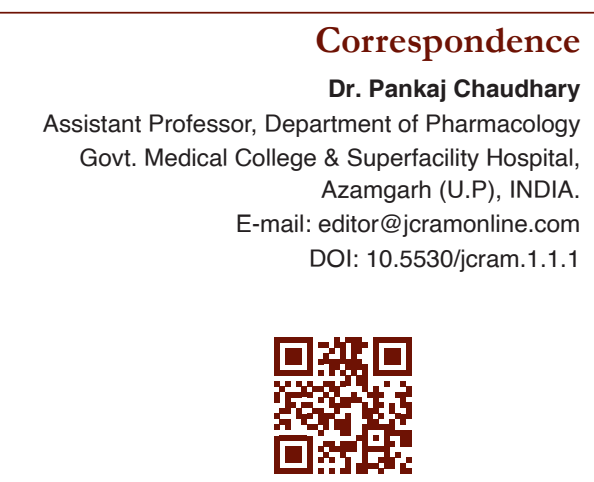

www.jcramonline.com 